Proceedings of the ASME $202039^{\text {th }}$ International

Conference on Ocean, Offshore and Arctic Engineering

OMAE2020

June 28-July 3, 2020, Diplomat Beach Resort, Fort Lauderdale, FL

OMAE2020-18731

\title{
PERIDYNAMIC ANALYSIS OF FRAGMENTATION OF ICE PLATE UNDER EXPLOSIVE LOADING WITH THERMAL EFFECTS
}

\author{
Yuan Zhang, Chao Wang*, Chunyu Guo \\ College of Shipbuilding Engineering, Harbin \\ Engineering University \\ Harbin, Heilongjiang 150001, China
}

\author{
Longbin Tao \\ Department of Naval Architecture, Ocean \& Marine \\ Engineering University of Strathclyde Glasgow, G4 \\ OLZ, UK
}

\section{ABSTRACT}

Along with the development in arctic region, the icebreaking technologies are gradually becoming the focus. As one of the most powerful and effective way to breaking ice, especially in the ability to solve ice jams, the study of the behaviour of the sea and river ice under dynamic loads is an urgent subject of scientific research and it attracts extensive attention. In addition, the temperature change in the process of ice failure cannot be neglected since that temperature plays an important role in the mechanical properties of the ice. In this study, a fully coupled thermoelastic ordinary state-based Peridynamic model is employed to investigate fragmentation of ice cover subjected to an underwater explosion. Both the deformation effect on the thermal effects and the thermal effects on deformation are taken into consideration. The pressure shocks generated by the underwater explosion are applied to the bottom surface of the ice cover for non-uniform load distributions. Crack propagation paths are investigated, the damage is predicted and compared with existing experimental results. The corresponding temperature distributions are also examined. Furthermore, the ice failure mode in both the top surface and the bottom surface of the ice sheet is investigated.

Keywords: Ice fragmentation, thermal effects, explosive loading.

\section{NOMENCLATURE}

$\mathbf{x} \quad$ Position of a material point

$\mathbf{x}^{\prime} \quad$ Position of family point of $\mathbf{x}$

$\mathbf{u}$ Displacement vector of the material point

u' Displacement vector of the material point

$t \quad$ Time

$\Delta t \quad$ Time step

$\rho \quad$ Mass density

$\underline{t} \quad$ Force density state

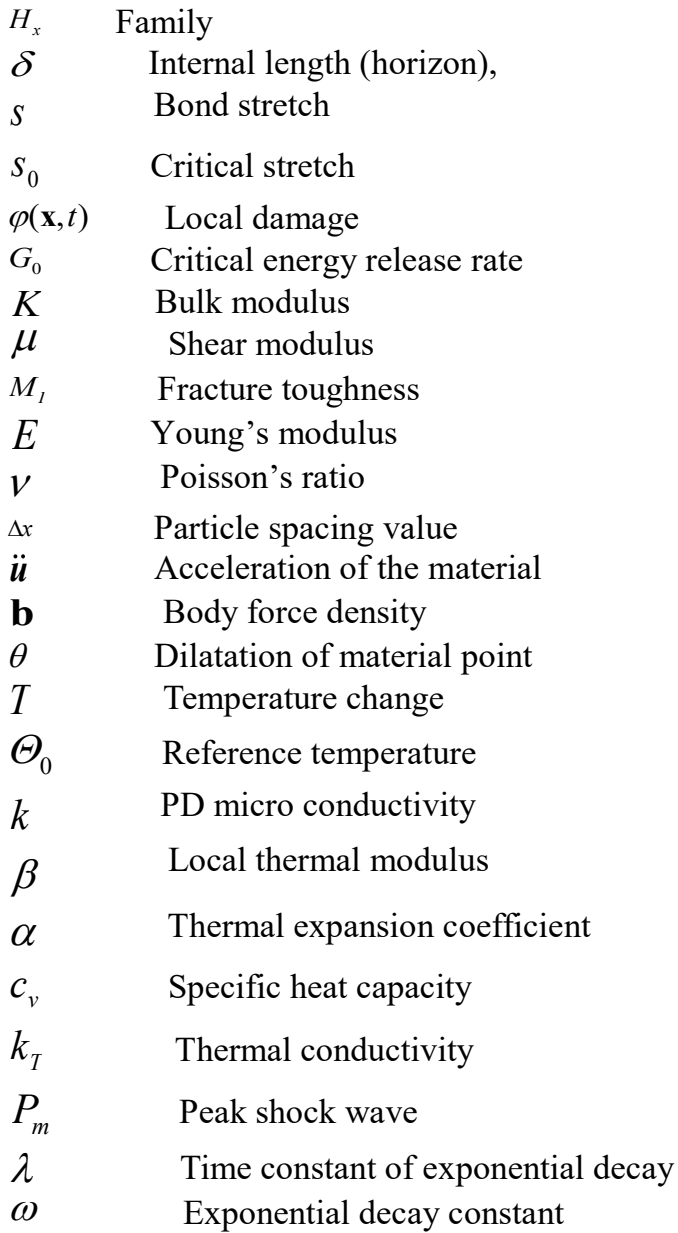

\section{INTRODUCTION}

Predicting fragmentation of ice cover caused by shock waves from blast loading is a challenging task in computational 
mechanics research. The engineering properties of ice are complex [1] and these are reviewed by Timco et al. and Petrovic $[2,3]$. This is due to its complex composition, the mechanical property variations controlled by the environment, as well as multiple phase transitions in the process of deformation, and in terms of destruction, generally may not have analogues [4]. Besides, the discontinuous issues in solid fracture and the presence of massive fragments are almost impossible to be represented using any interpolation field [5]. Consequently, it is necessary to develop an advanced method to study ice behaviour under shock loading.

There are three common ways to study the response of ice cover subjected to underwater explosion shock wave loads, i.e., the experimental method, the analytical method, and the numerical simulation method. The experimental method, if property conducted, can produce the most reliable results of ice damage and relationships between experimental variables (for instance, parameters of charges, the distance between charges and ice cove, and characteristics of ice cover) and blast effects. There have been a number of field experiments on the dynamic response of the ice under the action of the explosion wave [615]. However, since the destruction of ice cover under explosion takes place in a short moment, limited data can be collected during this process [16-18]. Most likely, such research has become a bibliographic rarity [9]. Very limited research work was conducted by the laboratory test. A test of icebreaking by a collapsing bubble was presented by Cui et al. [19] which carried out in a cubic glass water tank of $0.3 \mathrm{~m}$ in length. This work concentrated on the behaviour of bubbles than the damage response of ice.

An analytical method based on elastics vibration theory for thin plate was applied to the analysis of the dynamic response of the icecap structure under explosion wave [15]. Only the dynamic loads was obtained by the model. Another analytical model is based on the macroscopic theory of continuum mechanics [20]. This model considers the destruction of materials, for example, ice. It is noted that analytical solutions are mainly limited to special and simple cased [21].

As for the numerical method, the finite element method (FEM) is frequently used in modelling and simulating failure process of ice in the events of explosion condition. A computer model is developed for investigating ice-breaking by impulsive loading based on a specially developed finite element code [22]. Numerical simulation and pressure prediction of the dynamic response of ice cover subjected to underwater explosion by group charge were carried by Xing et al. [23]. Unfortunately the element failure was not allowed in the work. The failure characteristics of $20 \mathrm{~cm}$ thick ice when a certain amount of TNT exploded underwater at different depths were studied using LSDYNA [24]. In continuum mechanics, where FEM is widely used, the solution of the governing equation is related to the partial derivatives of displacement. which are undefined owing to the discontinuous displacement field along the cracks [25]. In addition, Orlov et al. [20] proposed a numerical model which is the development of Johnson's method for solving modern multi-contact problems of the mechanics of a deformable solid.
The numerical method contains a new way for isolating the surfaces of discontinuity of materials. Although a variety of methods were applied to study the ice behavior under dynamic loading, the concepts of ice destruction are still yet fully understood, especially there are no adequate mathematical models of the behavior of ice under dynamic loads [20, 26, 27]. To the authors' knowledge, there is no public literature related to the numerical analysis of ice damage by blast loading with thermal consideration.

Peridynamics (PD) is a relatively new formulation of the equation of motion in continuum mechanics which has already applied in various engineering problems, especially in discontinuous problems because of its strong ability to predict crack propagation [28]. In this study, fully coupled thermoelastic ordinary state-based Peridynamic is employed, and the fragmentation of the ice sheet is simulated with both mechanical model coupled with thermal model. The corresponding temperature distributions are investigated. The damage and crack propagation of the ice plate for both surfaces of the ice sheet are analyzed and compared to uncoupled cases. The newly developed numerical model is further validated against the existing experimental results.

\section{METHODOLOGY}

\section{Govern equation}

At a certain time $t$, the state of a material point $\mathbf{X}$ is influenced by material points (such as $\mathbf{x}^{\prime}$ ) located within a region of finite radius $\delta . \delta$ is called the internal length (horizon). The motion state of the material point is the result of the interaction of external forces and all points in its horizon. All neighbourhood points within the distance $\delta$ are called the family of $\mathbf{X}$, which is expressed as $H_{x}$. Hence, the interaction force exists only in $H_{x}$, beyond $H_{x}$ the influence of the material points $\mathbf{X}$ interacting with is assumed to vanish, as shown in Figure 1.

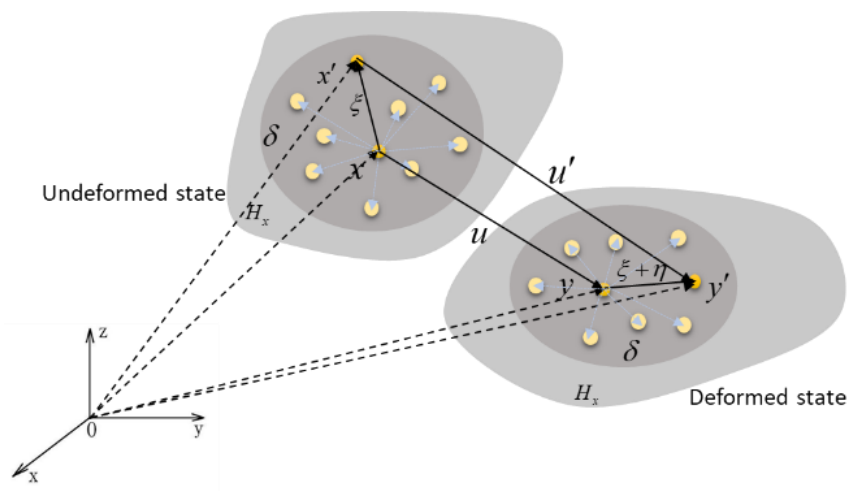

FIGURE 1: Material point $\mathbf{X}$ interacts with those in the sphere through bonds

The bond stretch or bond strain $S$ defined by [29]: 
$s=\frac{\left|y^{\prime}-y\right|-\left|x^{\prime}-x\right|}{\left|x^{\prime}-x\right|}$

The PD governing equations for any particles of position $\mathbf{X}$ and time $t$ at a reference configuration can be expressed as following [30, 31]:

$\rho(\boldsymbol{x}) \ddot{\boldsymbol{u}}(\boldsymbol{x}, t)=\int_{H_{X}}\left\{\underline{t}[\boldsymbol{x}, t]\left\langle\boldsymbol{x}^{\prime}-\boldsymbol{x}\right\rangle-\underline{t}^{\prime}\left[\boldsymbol{x}^{\prime}, t\right]\left\langle\boldsymbol{x}-\boldsymbol{x}^{\prime}\right\rangle\right\} \frac{\boldsymbol{y}^{\prime}-\boldsymbol{y}}{\left|\boldsymbol{y}^{\prime}-\boldsymbol{y}\right|} d V_{x^{\prime}}+\boldsymbol{b}(\boldsymbol{x}, t)$

where $\mathbf{u}$ and $\boldsymbol{u}^{\prime}$ are the displacement vectors of the material point $\mathbf{x}$ and $\mathbf{x}^{\prime}$ after deformation, $\rho$ is the mass density, $V$ is the volume, $\ddot{\boldsymbol{u}}$ is the acceleration. The force density $t[\boldsymbol{x}, t]$ and $t^{\prime}\left[x^{\prime}, t\right]$ are force states defined as the force per unit volume that the material point at $\mathbf{x}^{\prime}$ exerts on the material point at $\mathbf{x}$. b is a prescribed body force density field.

\section{Thermoelastic model}

By using the relationship between the force density vector and the strain energy density, force vectors are derived by [30]. By performing the necessary algebraic manipulations, the equation of motion for ordinary state-based PD including the effect of temperature change is finally written as [29]:

$\rho(\boldsymbol{x}) \ddot{\boldsymbol{u}}(\boldsymbol{x}, t)=\int_{H_{x}}\left\{\frac{2 \delta d \Lambda a}{\left|\boldsymbol{x}^{\prime}-\boldsymbol{x}\right|}\left(\theta+\theta^{\prime}\right)+4 \delta b\left(s-\alpha \frac{\left(T+T^{\prime}\right)}{2}\right)\right\}\left\{\frac{\boldsymbol{y}^{\prime}-\boldsymbol{y}}{\left|\boldsymbol{y}^{\prime}-\boldsymbol{y}\right|} d V^{\prime}+\boldsymbol{b}(\boldsymbol{x}, t)\right.$

where $T$ represents the temperature change of point $x$ with respect to the reference temperature $\Theta_{0}, T=\Theta(x, t)-\Theta_{0}$. Similarly, $T^{\prime}$ is the temperature change of point $x^{\prime}$. The dilatations $\theta$ for material point $x, \theta^{\prime}$ for material point $x^{\prime}$, are defined as [29]:

$$
\begin{aligned}
& \theta=\int_{H_{X}} d \delta(s-\alpha T) \Lambda d V \\
& \theta^{\prime}=\int_{H_{X}} d \delta\left(s-\alpha T^{\prime}\right) \Lambda d V^{\prime}
\end{aligned}
$$

The heat conduction equation in the fully coupled thermomechanical PD model was derived by [32]:

$\rho c_{v} \dot{T}(\boldsymbol{x}, t)=\int_{H_{X}}\left\{k \frac{T-T^{\prime}}{\left|\boldsymbol{x}^{\prime}-\boldsymbol{x}\right|}-\Theta_{0} \beta\left(\boldsymbol{x}^{\prime}-\boldsymbol{x}\right) \dot{e}\left(\boldsymbol{x}^{\prime}-\boldsymbol{x}\right)\right\} d V^{\prime}+h_{s}(\boldsymbol{x}, t)$

where $c_{v}$ is the specific heat capacity under constant volume. $k$ is PD micro conductivity and it is decided by thermal conductivity $k_{T}$. $\dot{e}$ is the time rate of change of stretch. $k$ and $\dot{e}$ are derived in [33].

\section{Failure criterion}

The critical stretch value is $[29,30]$ :

$$
s_{c}= \begin{cases}\sqrt{\frac{G_{c}}{\left(3 \mu+\left(\frac{4}{3}\right)^{4}(K-2 \mu)\right) \delta}} & \text { for 3D } \\ \sqrt{\frac{G_{c}}{\left(\frac{6}{\pi} \mu+\left(\frac{16}{9 \pi^{2}}\right)(K-2 \mu)\right) \delta}} & \text { for } 2 \mathrm{D}\end{cases}
$$

where $G_{c}$ is fracture toughness, which reflects the resistance of the material to brittle fracture. $K$ is bulk modulus and $\mu$ is the shear modulus. $G_{c}$ can be expressed by fracture toughness $K_{I}$ for ice [3]:

$G_{c}=\frac{K_{I}^{2}}{E}$

In order to measure the failure of the material, a quantity known as local damage at a point is proposed as [30]:

$\varphi(\mathbf{x}, t)=1-\frac{\int_{H_{x}} \mu(\mathbf{x}, t, \xi) d V_{\xi}}{d V_{\xi}}$

\section{NUMERICAL IMPLEMENTATION}

The thermal equation Eq. (3) and motion equation Eq. (2) are solved simultaneously by explicit time integration at each time step in FORTRAN. The details on the discretized form of Eq. (2), Eq. (3), Eq. (4), and Eq. (8) and the computational procedure are similar to that described in $[29,33]$, while the surface effects and volume corrections follow the same procedure in [30]. To obtain convergent results of an explicit time integration scheme, the time step size $\Delta \mathrm{t}$ and the horizon $\delta=3.015 \Delta x$ are calculated as suggested by [30].

The thermal OSB-PD model is used to predict the damage of ice under explosive loading which was previously studied by BB-PD in [5] with the extension of thermal effects on deformation and crack path. It is noted that the OSB-PD which eliminates the restriction on Poisson's ratio. The self-contact of the ice is not considered in present work because the ice damage is mostly caused by shock wave rather than self-contact. The mechanical and thermal properties are list in Table 1.

TABLE 1: Material properties of ice[5,34]

\begin{tabular}{cccc}
\hline \multicolumn{2}{c}{ Mechanical properties } & \multicolumn{2}{c}{ Thermal properties } \\
\hline$E$ & $1.229 \mathrm{Gpa}$ & $\Theta_{0}$ & $263.15 \mathrm{~K}^{-1}$ \\
$v$ & 0.33 & $\alpha$ & $51.9 \times 10^{-6} \mathrm{~K}^{-1}$ \\
$\rho$ & $896.977 \mathrm{~kg} / \mathrm{m}^{3}$ & $c_{v}$ & $2000 \mathrm{~J} /(\mathrm{kgK})$ \\
$M_{I}$ & $134 \mathrm{kPam}^{0.5}$ & $k_{T}$ & $2.3 \mathrm{~W} /(\mathrm{mK})$ \\
\hline
\end{tabular}

As illustrated in Figure 2, the numerical model of ice cover is in a circular shape with a diameter of $51.2 \mathrm{~m}$ which is large enough to avoid the effect of the boundaries [5]. The thickness of the model is the same as $h=0.6 \mathrm{~m}$. The grid size for discretization is $\Delta x=0.2 \mathrm{~m}$. This model contains total of 154,404 material points. The time step for the explicit time integration is set to $\Delta t=0.5 \times 10^{-5}$ according to stability criterion [30]. The total simulation time is set as $0.024 \mathrm{~s}$ [5]. 


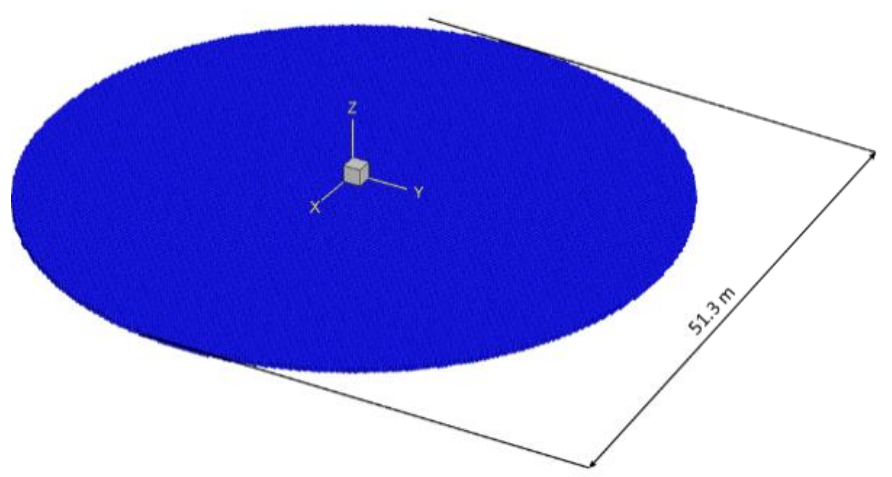

FIGURE 2: Geometry dimension illustration of test ice cover and its discretization

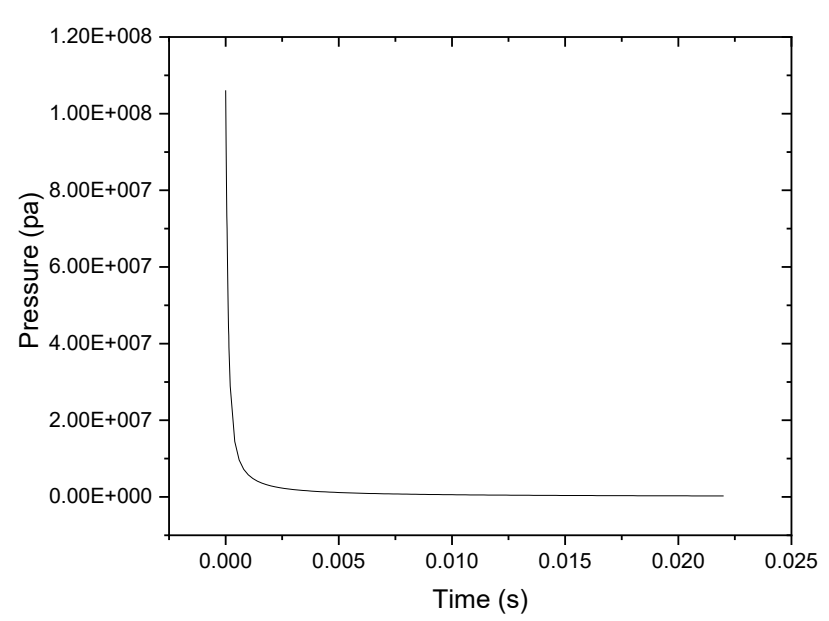

FIGURE 3: Recession curve of shock pressure

The present investigation adopts the empirical shock pressure [5]:

$P_{m}=\left\{\begin{array}{cc}4.41 \times 10^{7}\left(\frac{W^{1 / 3}}{R}\right)^{1.5} & 6 \leq \frac{R}{R_{0}}<12 \\ 5.24 \times 10^{7}\left(\frac{W^{1 / 3}}{R}\right)^{1.13} & 12 \leq \frac{R}{R_{0}}<240\end{array}\right.$

where $P_{m}$ is peak shock pressure, $W$ is charge weight. $R$ is the distance between charge and target. $R_{0}=[3 W /(4 \pi \times 1600)]^{1 / 3}$ is the radius of spherical satchel charge. In the present work, the charge is emulsion explosive of $10 \mathrm{~kg}$. It is located at $1.2 \mathrm{~m}$ away from the ice cover while the decay of the shock wave is described as $[5]$ :

$P_{t}=\left\{\begin{array}{lr}P_{m} \cdot e^{-\frac{t}{\lambda}} & 0 \leq \mathrm{t}<\lambda \\ 0.368 P_{m} \frac{\lambda}{t} & \lambda \leq \mathrm{t}<100-150 \lambda\end{array}\right.$

where acoustic velocity $v_{a}$ is $v_{a}=1500 \mathrm{~m} / \mathrm{s} . \lambda$ is the time constant of exponential decay and can be expressed as: $\lambda= \begin{cases}0.45 R_{0}\left(\frac{R}{R_{0}}\right)^{0.45} \times 10^{-3} & \frac{R}{R_{0}} \leq 30 \\ 3.5 \frac{R_{0}}{v_{a}} \sqrt{\lg \frac{R}{R_{0}}-0.9} & \frac{R}{R_{0}}>30\end{cases}$

Figure 3 shows the pressure imparted by the shock wave with a distance of $1.2 \mathrm{~m}$.

The non-uniform loading for near field explosion and a decoupled approach are utilized to express the shock pressure acting on ice surface. The pressure shock is in the form of $P(r, t)=\mathrm{P}_{\mathrm{r}}(r) \cdot P_{t}(t)$ [35]. The pressure distribution of shock effects is further expressed as:

$P(r, t)=\left\{\begin{array}{cl}P_{t} & \mathrm{r} \leq \mathrm{r}_{0} \\ P_{t} e^{-\omega\left(r-r_{0}\right)} & \mathrm{r}_{0} \leq \mathrm{r}<\mathrm{r}_{p} \\ 0 & \mathrm{r}_{p} \leq \mathrm{r}\end{array}\right.$

where $r$ represents the distance from the collective material point to the centre of the ice plate. $r_{0}$ is the radius of the explosive disc used in the experiments which is $0.15 \mathrm{~m}$ in the experiment. $\mathrm{r}_{p}$ is the radium of the ice plate. $\omega=0.8$ is an exponential decay constant which models the pressure distribution over the exposed area of the ice cover surface.

\section{RESULTS AND DISCUSSION}

\section{The top surface}

The uncoupled crack propagation pattern and coupled crack propagation pattern with corresponding temperature change distribution of the top surface of the ice cover at time history are presented in Figure 4. For the uncoupled case, both the damage area and transition zone present a circular outline and increases with time. They expand considerably at the begining followed by the stage with a steady radius of fracture zone. For the coupled case, it can be found that the evolution process of ice damage is similar to the coupled case in terms of the time history. However, different crack propagation pattern and damage degree are observed as clearly demonstrated at $t=22.0 \mathrm{~ms}$ in Figure 4 (c1) and Figure 4 (c-2). Fewer cracks are observed in the coupled case while the damage level is more extensive. Considering the small temperature changes induced by the applied pressure, the coupling term effect on damage is obvious. In addition, radial crack growth in the coupled case is longer and faster. As to the temperature distribution, the temperature increases along the cracks and the boundary of the fracture zone which is observed at all time steps. In the fracture zone, the temperature drop is clearly observed since that ice body in this area is fully fractured. The temperature growth in the most central part shown in Figure 4 (b-3) and (c-3) might be caused by unconstrained free movement of material particles after complete destruction. 


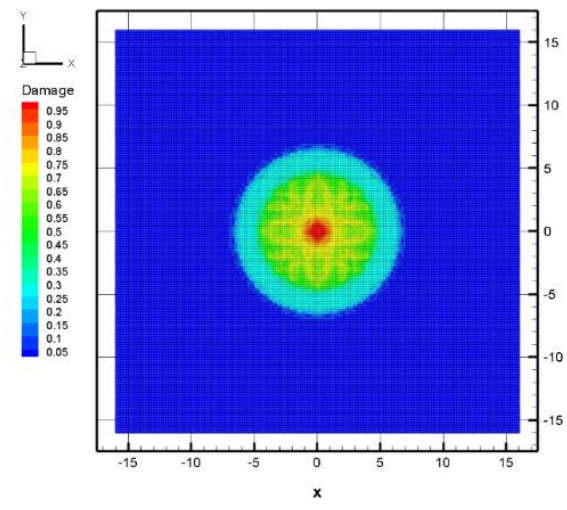

(a-1) uncoupled damage plot

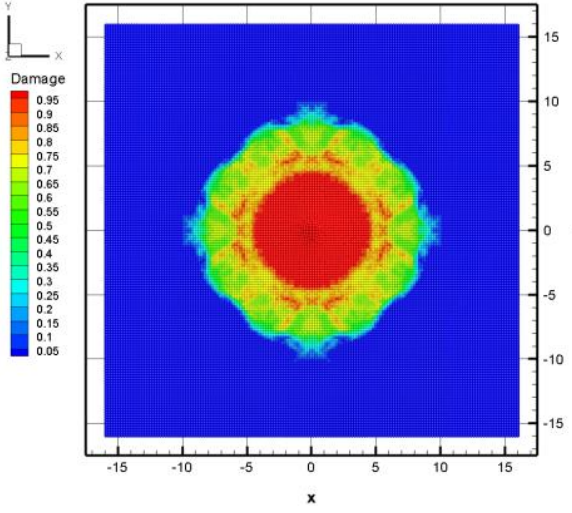

(b-1) uncoupled damage plot

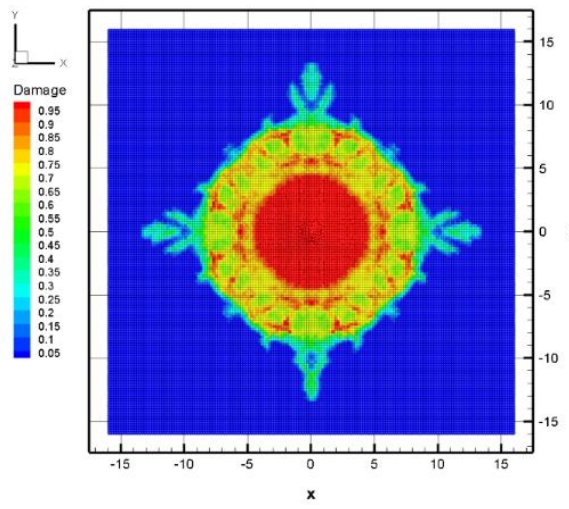

(c-1) uncoupled damage plot

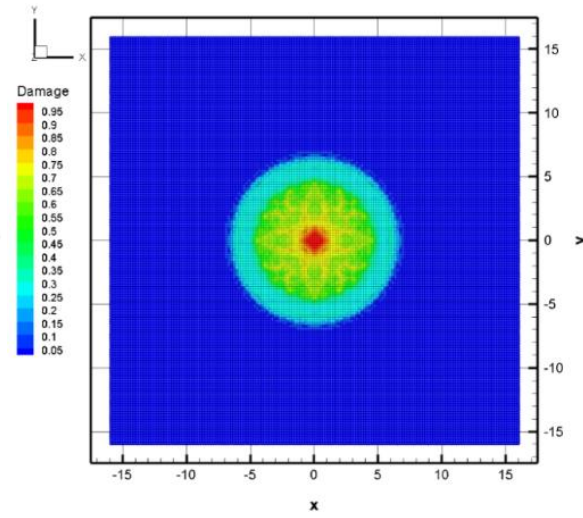

(a-2) coupled damage plot (a) $t=3.0 \mathrm{~ms}$

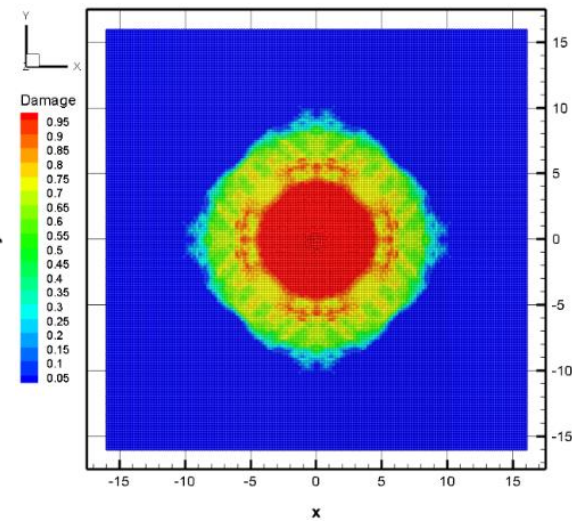

(b-2) coupled damage plot (b) $t=15.0 \mathrm{~ms}$

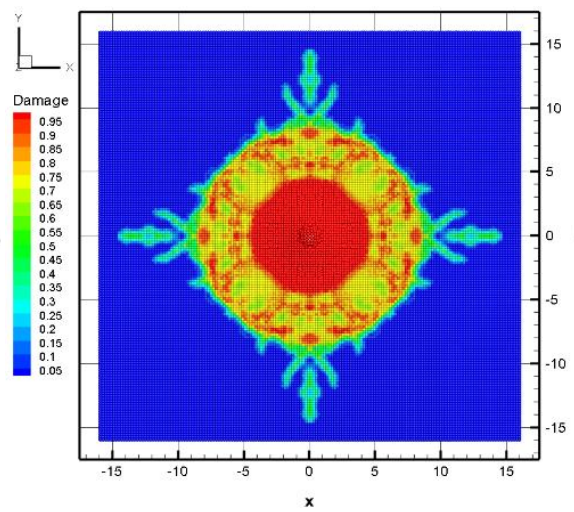

(c-2) coupled damage plot (c) $t=22.0 \mathrm{~ms}$

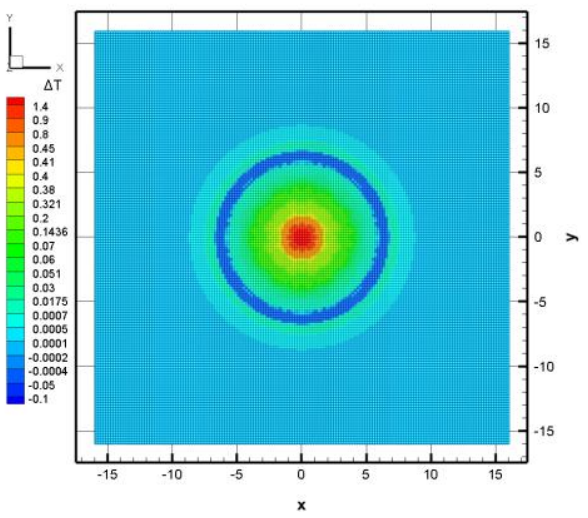

(a-3) temperature distribution

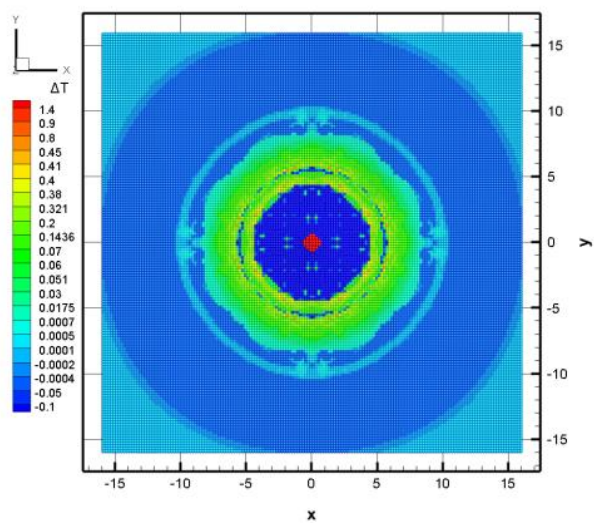

(b-3) temperature distribution

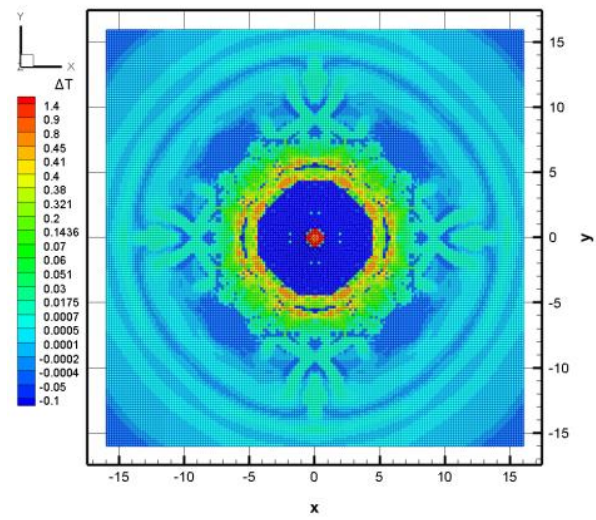

(c-3) temperature distribution

FIGURE 4: Damage plots and temperature change of the top surface of the ice plate at different time steps

By observing the snapshot taken from the experiment, in Figure 5, carried out in Yellow river in Baotou, the ice is broken by the shock wave and has a range of failure area. The holeshaped failure area is measured by its' radius $\left(R_{b}\right) /$ diameter shown in Red circle in Figure 5. Outside the damaged area, the radial cracks and circumferential cracks are also observed which is known as cracked zone or transition region as depicted in
Figure 6. This phenomenon has also been confirmed by most icebreaking experiments by underwater explosions. In view of this, the damage results of the numerical calculation are in good agreement with those of experiments. To further illustrate this, the final shape of the damage area is shown in Fig. 6 which also describes the crack path of the ice plate. It can be found that the failure area is similar to the shape of a circular hole, and the 
radius $R_{b}$ of the hole is measured as $5.22 \mathrm{~m}$ in the experiment and $5.20 \mathrm{~m}$ in the simulation respectively. The radius of the numerical simulation is very close to that of the experimental radius.

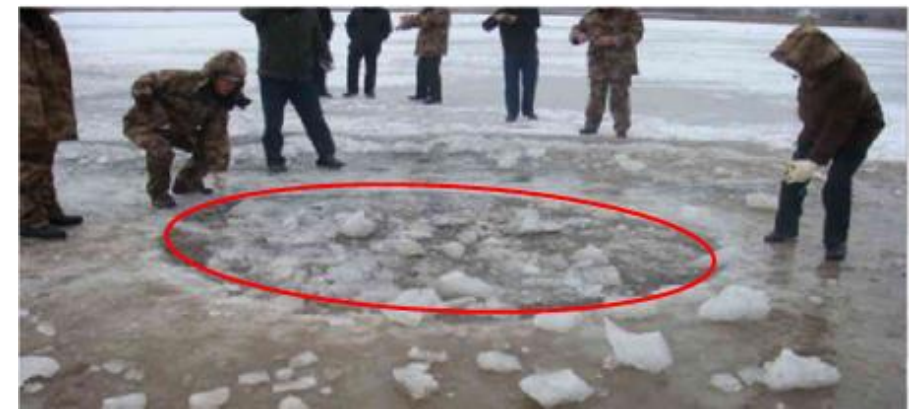

FIGURE 5: The snapshot of ice damage by blast loading in the field experiment[36]

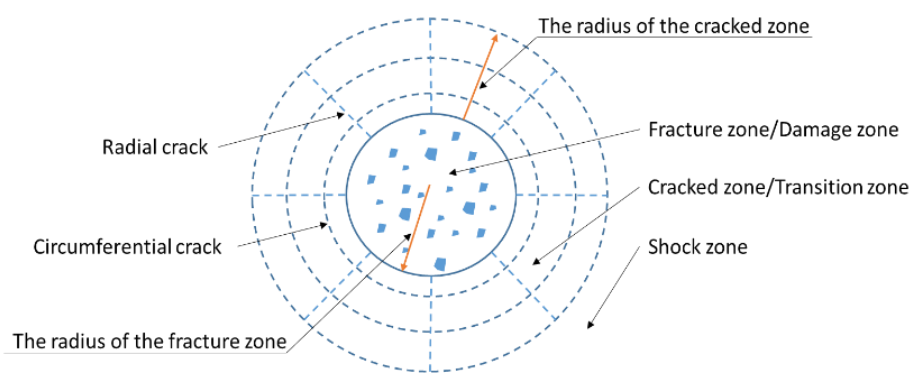

FIGURE 6: Schematic diagram of ice damage by explosion load

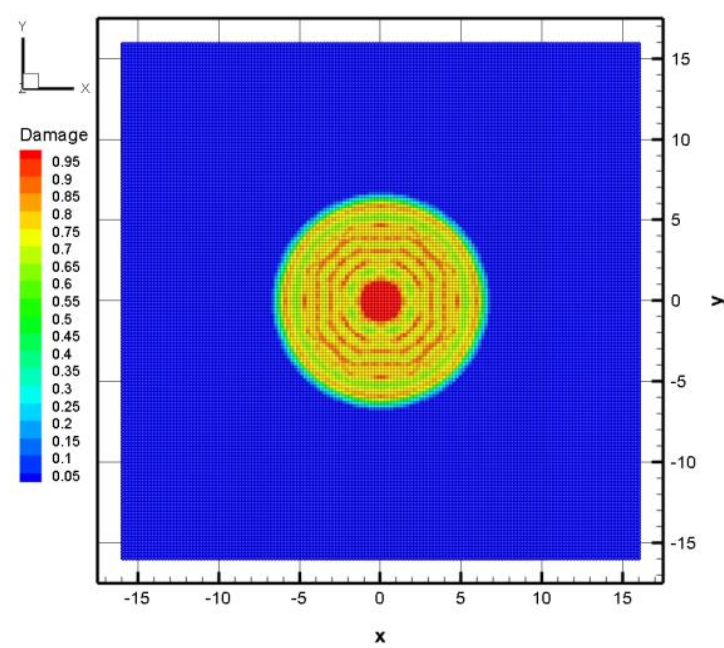

(a) Damage at $t=3.0 \mathrm{~ms}$

\section{The bottom surface}

It is worthnoting that the damage and temperature distribution on the bottom surface of the ice cover is significantly different from that of the top surface of the ice cover. Both mechanical (uncoupled) and thermomechanical (coupled) simulation present such characteristic. As shown in Fig. 7 which depicts the bottom view of the fragmentation and the temperature distribution for the coupled case of the ice cover at time process, although the fracture zone tends to be larger as time progresses which exhibits the similar damage development with the top surface, the significant differences of failure modes are observed. By comparing Figure 7 with Fig. 4, the bottom has a larger radius of damage area with $6.2 \mathrm{~m}$. However, the transition region almost disappears and its radius is even less than a third of the radius of the damage area in spite of the initial damage plot at $3.0 \mathrm{~ms}$. In addition, the boundary of the failure area is smoother. This is probably because the bottom side of the ice sheet is in direct contact with the shock wave rather than the top side of the ice sheet. Accordingly, it bears greater pressure instead of the top. Then, the force transmitted to the top surface of the ice sheet is smaller than the original value. As a result, the more seriously damaged phenomenon in the bottom surface of the ice sheet is apparent. Just like the top surface, the temperature change distributions have a similar trend with crack growth in Damage plots. It can be seen that as the destruction spreads out, the temperature changes of PD nodes decreases. There is a temperature drop where the local tension is clearly showed in the edge of damage area.

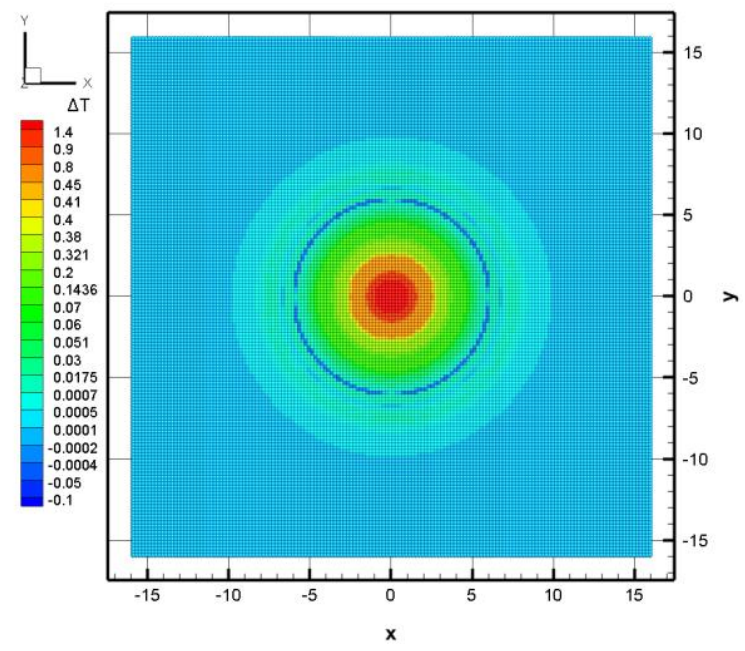

(b) Temperature change $t=3.0 \mathrm{~ms}$ 


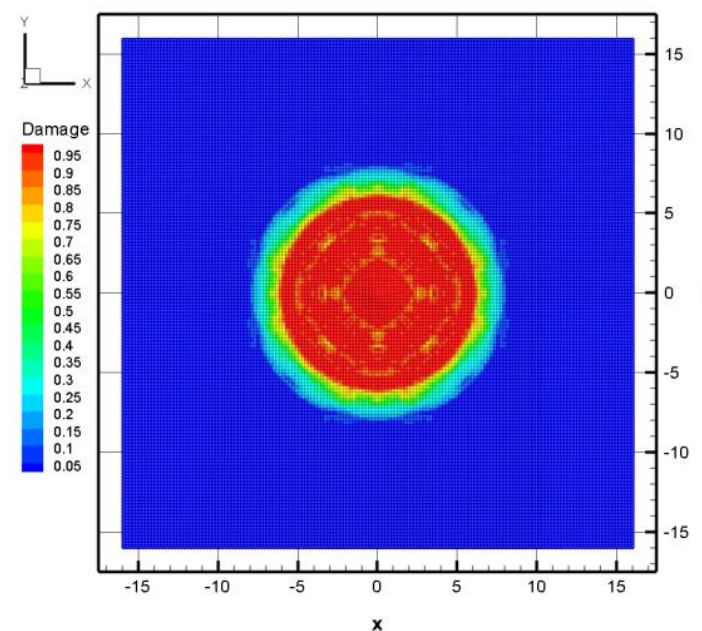

(c) Damage at $t=11.0 \mathrm{~ms}$

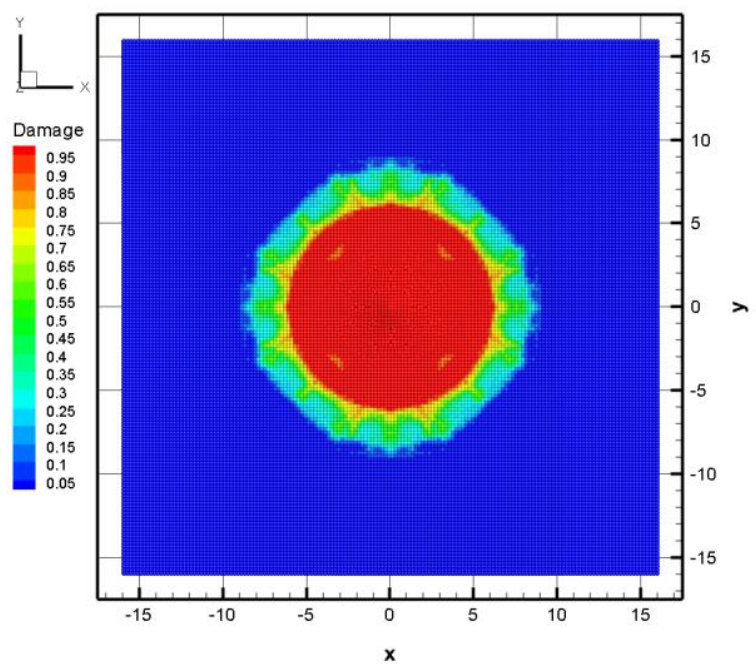

(e) Damage at $t=13.6 \mathrm{~ms}$

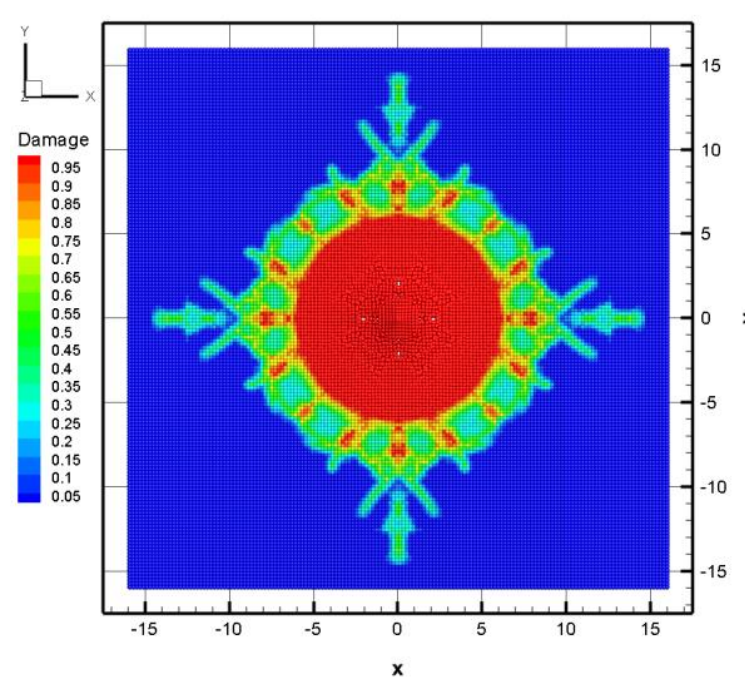

(g) Damage at $t=22.0 \mathrm{~ms}$

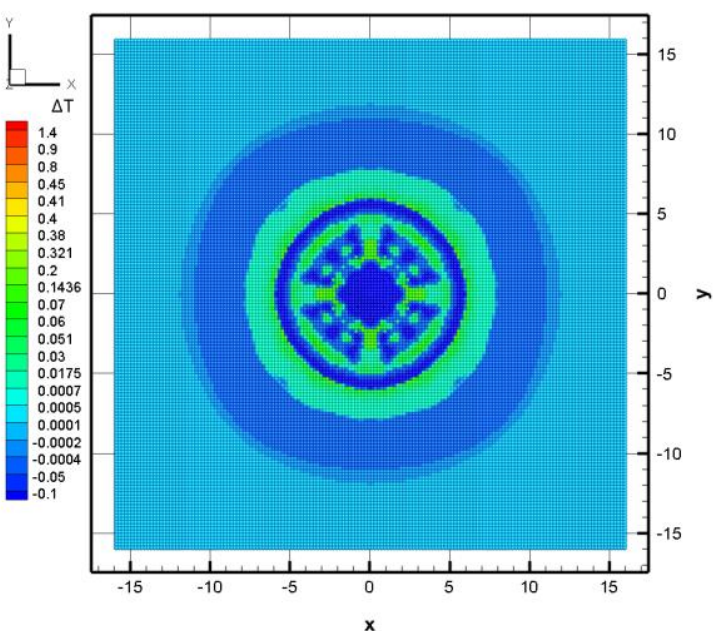

(d) Temperature change $t=11.0 \mathrm{~ms}$

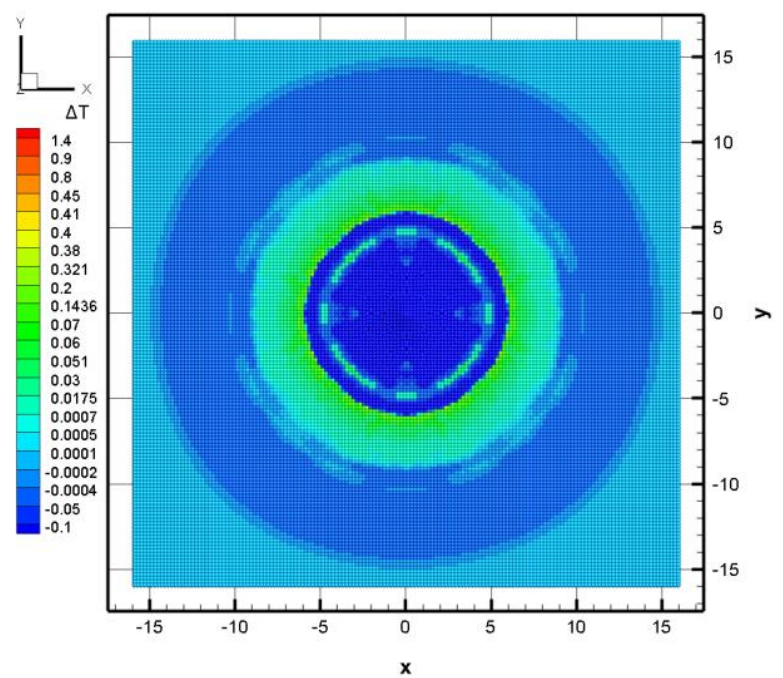

(f) Temperature change $t=13.6 \mathrm{~ms}$

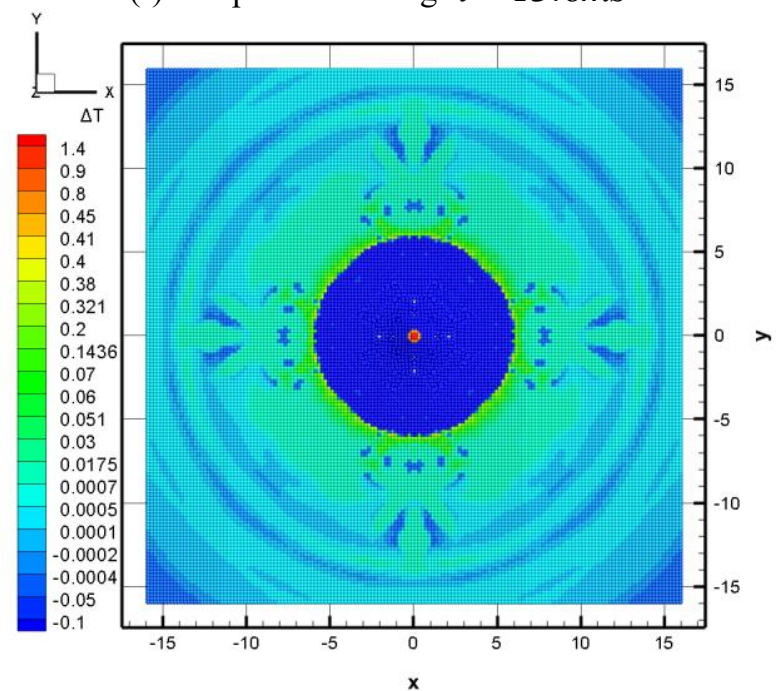

(h) Temperature change $t=22.0 \mathrm{~ms}$

FIGURE 7: Damage plots and temperature change of the bottom surface of the ice plate at different time steps in coupled case 


\section{Conclusions}

In the present study, an ordinary state-based PD model with fully coupled thermal effects is developed to study the ice fragmentation of the ice plate under shock loading. Both the failure of ice body of the temperature field and the effect of temperature change on the damage are taken into consideration in the generalized PD model. It is found that the damage area of both the top and the bottom of the ice plate increases rapidly within the initial $11.0 \mathrm{~ms}$ followed by the cracks propagate in the transition zone. The ice damage exhibits different patterns between the two surfaces. The PD-predicted damage pattern and damage radius agree well with the experimental results. Furthermore, the temperature change distributions present similar patterns with crack propagations. Results showed that the thermal term influences crack propagation pattern and damage level. The newly developed PD model can be used for predicting more realistic thermal and mechanical properties of ice by further considering the ice damage strength caused by temperature change.

\section{ACKNOWLEDGEMENTS}

This research was financially supported by the National Natural Science Foundation of China (Grant No. 51679052 and No. 51809055), the Natural Science Foundation of Heilongjiang Province of China (Grant NO. E2018026), the high technology ship of MIIT (Grant No. 2017-614) and the Defense Industrial Technology Development Program (Grant No. JCKY2016604B001).

\section{REFERENCES}

[1] Tryde, P., 1980, "Physics and Mechanics of Ice," Naturwissenschaften, 67(11), pp. 556-559.

[2] Petrovic, J., 2003, "Review mechanical properties of ice and snow," Journal of materials science, 38(1), pp. 1-6.

[3] Timco, G. W., and Weeks, W. F., 2010, "A review of the engineering properties of sea ice," Cold Regions Science and Technology, 60(2), pp. 107-129.

[4] Bogorodskii, V., and Gavrilo, V. J. L., Gidrometeoizdat, 1980, "Ice. Physical properties. Modern methods of glaciology," p. 232.

[5] Wang, Q., Wang, Y., Zan, Y. F., Lu, W., Bai, X. L., and Guo, J., 2018, "Peridynamics simulation of the fragmentation of ice cover by blast loads of an underwater explosion," Journal of Marine Science and Technology, 23(1), pp. 52-66.

[6] Mellor, M., 1986, "Blasting and Blast Effects in Cold Regions. Part 2. Underwater Explosions," COLD REGIONS RESEARCH AND ENGINEERING LAB HANOVER NH.

[7] Mellor, M., and L'Heureux, D., 1988, "Eruptions from UnderIce Explosions," COLD REGIONS RESEARCH AND ENGINEERING LAB HANOVER NH.
[8] Leslie, D. M., and Nelson, C. A., 1961, "Explosion tests under thick polar ice," NAVAL ORDNANCE LAB WHITE OAK MD.

[9] Orlov, M., 2019, "Investigation of the process of explosive loading of freshwater ice," Thermal Science, 23(Suppl. 2), pp. 561-567.

[10] Orlov, M. Y., Orlova, Y., Bogomolov, G., and Glazyrin, V., "Research of the behavior of ice on water under explosive loads," Proc. Journal of Physics Conference Series.

[11] Zamyshlyaev, B. V., and Yakovlev, Y. S., 1973, "Dynamic loads in underwater explosion," NAVAL INTELLIGENCE SUPPORT CENTER WASHINGTON DC TRANSLATION DIV.

[12] Orlova, Y. N. J. C. S. D., 2016, "Comprehensive theoretical and experimental study of the behavior of ice under shock and explosive loads."

[13] Wang, Y., Xiao, W., Yao, X., and Qin, Y., 2019, "Fragmentation of ice cover subjected to underwater explosion shock wave load and its influence factors," Explosion And Shock Waves, 39(7).

[14] Orlova, Y. N., and Orlov, M. Y., 2015, "The Study of the Process of Explosive Loading of Ice," Vestnik Tomskogo Gosudarstvennogo Universiteta-Matematika I MekhanikaTomsk State University Journal of Mathematics and Mechanics(38), pp. 81-89.

[15] Ma, W., Xie, W., Liu, D., and Zhang, D., "Analysis of the dynamic response of the icecap structure under the action of explosion wave," Proc. 2011 International Conference on Electric Technology and Civil Engineering (ICETCE), IEEE, pp. 95-98.

[16] Barash, R. M., 1966, "Ice-breaking by explosives," NAVAL ORDNANCE LAB WHITE OAK MD.

[17] Meilor, M. J. U. C. R. R., 1972, "Data for ice blasting," 46(8), pp. 34-50.

[18] Mellor, M., 1982, "Breaking ice with explosives," COLD REGIONS RESEARCH AND ENGINEERING LAB HANOVER NH.

[19] Cui, P., Zhang, A. M., Wang, S. P., and Khoo, B. C., 2018, "Ice breaking by a collapsing bubble," Journal of Fluid Mechanics, 841, pp. 287-309.

[20] Orlov, M. Y., Glazyrin, V., Orlov, Y. N., and Orlova, Y. N., "Research of ice behavoir under shock and explosive loads. Numerical simulation and experiment," Proc. Journal of Physics: Conference Series, IOP Publishing, p. 012001.

[21] Gao, Y., and Oterkus, S., 2018, "Peridynamic Analysis of Marine Composites under Shock Loads by Considering Thermomechanical Coupling Effects," Journal of Marine Science and Engineering, 6(2), p. 38.

[22] Mansour, A., and Seireg, A., 1983, "A Computer-Based Simulation of Ice-Breaking by Impact," Journal of Energy Resources Technology-Transactions of the Asme, 105(4), pp. 448-453.

[23] Xing, Y. M., Zheng, T., and Wang, H. H. J. J. o. E. M., 2010, "Numerical Simulation of Ice Cover Dynamic Response Subjected to Group Charge Underwater Explosion," Journal of Experimental Mechanics. 
[24] Meng, W. Y., Xin, L., and Hu, J. Q., 2013, "Based on the technology of shaped charge numerical simulation and experiment research of ice blasting," Materials Processing and Manufacturing Iii, Pts 1-4, 753-755(3), pp. 2704-2708.

[25] Chen, Y., Lee, J., Eskandarian, A. J. T., and mechanics, a. f., 2002, "Dynamic meshless method applied to nonlocal crack problems," 38(3), pp. 293-300.

[26] Schulson, E. M., and Duval, P., 2009, Creep and fracture of ice.

[27] Stewart, S. T., and Ahrens, T. J. J. J. o. G. R. P., 2005, "Shock properties of $\mathrm{H} 2 \mathrm{O}$ ice," 110(E3).

[28] Diehl, P., Prudhomme, S., Lévesque, M. J. J. o. P., and Modeling, N., 2019, "A review of benchmark experiments for the validation of peridynamics models," 1(1), pp. 14-35.

[29] Gao, Y., and Oterkus, S., 2018, "Ordinary state-based peridynamic modelling for fully coupled thermoelastic problems," Continuum Mechanics and Thermodynamics, 31(4), pp. 907-937.

[30] Madenci, E., and Oterkus, E., 2014, "Peridynamic Theory and Its Applications."

[31] Silling, S. A., Epton, M., Weckner, O., Xu, J., and Askari, E., 2007, "Peridynamic states and constitutive modeling," Journal of Elasticity, 88(2), pp. 151-184.

[32] Oterkus, S., Madenci, E., and Agwai, A., 2014, "Fully coupled peridynamic thermomechanics," Journal of the Mechanics and Physics of Solids, 64, pp. 1-23.

[33] Oterkus, S., Madenci, E., and Agwai, A., 2014, "Peridynamic thermal diffusion," Journal of Computational Physics, 265, pp. 71-96.

[34] Engineering ToolBox, (2004). Ice - Thermal Properties. [online] Available at: https://www.engineeringtoolbox.com/icethermal-properties-d_576.html [Accessed Day Mo. Year].

[35] Langdon, G. S., Cantwell, W. J., Guan, Z. W., and Nurick, G. N., 2014, "The response of polymeric composite structures to air-blast loading: a state-of-the-art," International Materials Reviews, 59(3), pp. 159-177.

[36] Xu, G., 2014, "Based on the thechnolofy of shaped charge numerical simulation and experimetal research of single point ice blasting on the yellow river," Master, North China University of Water Resources and Electric Power. 